\title{
O NATURALISMO E A CRÍTICA À CAUSALIDADE EM DAVID HUME
}

\author{
Caio Leone de Almeida Moura Filho'; Wagner Teles de Oliveira² \\ 1. Bolsista PIBIC/CNPq, Graduando em Filosofia, Universidade Estadual de Feira de Santana, e-mail: \\ leone.gnosesophia@gmail.com \\ 2. Orientador, Departamento de Ciências Humanas e Filosofia, Universidade Estadual de Feira de Santana, e-mail: \\ wtoliveira@uefs.br
}

PALAVRAS-CHAVE: David Hume; Naturalismo; Causalidade

\section{INTRODUÇÃO}

A história da filosofia assimilou a obra de David Hume ao empirismo, fazendo da crítica à causalidade um dos principais signos da sua radicalidade e, por vezes, do seu ceticismo. A crítica à causalidade tem sua primeira, mas não menos sofisticada, formulação no Tratado da Natureza Humana. Assim, ao reservar-lhe a notoriedade pela formulação da crítica, a história da fílosofia sempre fizera questão de acentuar o aparente contraste entre, de um lado, a perturbadora denúncia segundo a qual não haveria relação necessária entre eventos empíricos e, de outro, a insatisfatória solução dada ao problema. Seja como for, o cerne da crítica à causalidade parece ser o diagnóstico segundo o qual as relações entre os eventos empíricos não poderiam senão ser exteriores aos próprios fenômenos, o que conduz a obra a uma funda reflexão sobre a unidade da experiência e da razão. Uma das mais importantes consequências da atribuição do epíteto de exterior às relações entre os fenômenos empíricos é situar tais relações como resultado da elaboração de um sujeito. Nesse contexto, a principal questão diz respeito ao estatuto da necessidade aplicada a um campo que não admite relações internas, ao contrário do que seria característico das matemáticas. Se por um lado a formulação do problema da causalidade consiste em fazer ver que as relações entre os fenômenos são exteriores e que, por isso mesmo, não há relação necessária entre eles, por outro, a solução consistirá na afirmação de que, embora sejam exteriores, as relações são necessárias. Agora, trata-se de afirmar um tipo de necessidade diferente daquele que é afirmado pelo caráter interno das relações. No entanto, ao que nos parece, tão importante quanto a afirmação do caráter exterior das relações é a concepção de natureza humana que ampara a solução dos problemas envolvidos na crítica à causalidade. Em sendo assim, se a formulação do problema afigura-se como tipicamente cético, a sua solução ganha ares de um naturalismo que, pelo menos à primeira vista, não parece conciliar-se com o espírito da formulação cética, mesmo porque é o próprio Hume que compreenderá ser tão cético o problema quanto a sua solução. A ênfase no contraste entre a formulação cética do problema e o quanto a solução tem de naturalista, tende a cindir a obra de Hume em dois gestos desiguais, recusando-lhe sua unidade. No entanto, razões internas à obra parecem indicar que ambos os momentos são legítimos e complementares. E não há melhor maneira de fazer ver que se trata de momentos complementares do que reconstituir as razões internas à obra, o que, nesse caso, significa recuperar as exigências conceituais pelas quais Hume retira e faz retornar, de uma maneira bem peculiar, a necessidade ao domínio do empírico e interrogar-se sobre o lugar do naturalismo na obra humeana. À medida que envolve o tema da necessidade e o da unidade da experiência, a pesquisa dialoga com o projeto "O Antipsicologismo e a Certeza em Wittgenstein", pois se aqui cumpre avaliar a perspectiva humeana segundo a qual a experiência delimita o campo do significativo a partir de uma noção de necessidade que resulta da crítica à razão, no projeto trata-se de examinar a relação 
entre lógica e empiria a partir de uma crítica ao psicologismo cujo principal componente consiste em delimitar o campo do significativo a partir das práticas.

\section{MATERIAL E MÉTODOS OU METODOLOGIA (ou equivalente)}

O método de pesquisa em filosofia consiste na leitura e escrita de textos segundo técnicas de exegese e de escrita que caracterizam a área. Assim, execução das atividades concernidas pelo plano de trabalho privilegiou o cotejo com as fontes primárias da pesquisa, sobretudo o Tratado da Natureza Humana, sem se furtar à apreciação de fontes secundárias, textos de destacados comentadores, que se inscrevem na tradição de leitura da obra de Hume, como, por exemplo, João Paulo Monteiro. Nesse sentido, o trabalho de pesquisa dividiu-se em duas etapas. Em uma primeira etapa, a da leitura, os textos indispensáveis à pesquisa foram cuidadosamente fichados. Em uma segunda etapa, a da escrita, uma vez vencida a etapa da leitura, foi elaborado um texto monográfico apresentado nas reuniões de nosso Grupo de Estudo e Pesquisa, de modo a permitir a apreciação dos resultados parciais da pesquisa por meio do debate das questões que ela envolve. A participação das reuniões semanais de nosso Grupo constitui um importante componente do método, pois permitiu ao bolsista, além de familiarizar-se com expedientes que são característicos da pesquisa na área, apresentar sistematicamente os resultados de sua pesquisa, perfazendo assim as condições para alcançar os resultados específicos do trabalho em filosofia.

\section{RESULTADOS E/OU DISCUSSÃO (ou Análise e discussão dos resultados)}

Nossa pesquisa consistiu na análise da obra de Hume, concentrando-se mais especificamente na crítica humiana à causalidade. De acordo com o naturalismo presente na obra de Hume, nossos conhecimentos são limitados e nossas expectativas sobre o futuro dependem das nossas experiências passadas. Nossas percepções tem um papel fundamental e podemos compreendê-las como constituindo dois gêneros distintos: impressões e ideias. As ideias são as cópias das impressões. Ideias e impressões são classificadas em simples e complexas (combinações, associação e relação necessária). As ideias e impressões complexas possuem dois objetos da razão no entendimento que são as questões de fatos (questões de hábito e crença) e relações de ideias. O Tratado é constantemente interpretado à luz do naturalismo e, segundo esta interpretação, Hume é um filósofo que se aproxima da ciência da natureza humana e dos princípios do entendimento, das paixões e dos costumes humanos. A experiência nos diz que a razão é escrava das paixões, pois a natureza desse sentimento é mais forte do que as reflexões da mente. Nas Investigações, os sentimentos, as crenças e os instintos naturais do homem são temas centrais à reflexão de Hume sobre a natureza do conhecimento e dos limites do entendimento humano, e sem o recurso da experiência nenhuma ideia ou percepção comum existiria na mente. O que representa a atitude naturalista do filósofo escocês é a atitude de quem pretende revolucionar a filosofia, assim como fez Newton com as ciências naturais. Na interpretação cética, por outro lado, Hume é um filósofo que duvida das potencialidades da razão e do entendimento, colocando um certo limite no entendimento humano, cuja fonte de conhecimento só pode ser a experiência, que é compreendida, assim, tanto como fonte do conhecimento quanto como determinação de seus limites. Nesse sentido, as duas principais obras de David Hume - Tradado da Natureza Humana e Investigações sobre o entendimento humano - teriam duas 
concepções filosóficas distintas, isto é, naturalismo e ceticismo, o que acaba por dividir a obra do filósofo em duas partes desiguais e comprometer toda a interpretação posterior de sua filosofia por desfazer da unidade da obra. Alguns especialistas identificam em Hume um naturalismo que supera o ceticismo pirrônico e estende a dúvida aos últimos limites da razão. Essa concepção filosófica diz que o costume é o guia da vida humana e não a razão. Outros, no entanto, argumentam em favor de um ceticismo mitigado e procura conciliar a interpretação cética de Hume com o naturalismo. Observamos que ambas as leituras não são incompatíveis e que a interpretação naturalista da crítica à causalidade de Hume não resolve o problema do Tratado da Natureza Humana, sendo a melhor maneira de conciliar as duas interpretações e garantir a unidade da filosofia humeana compreender que se trata de um ceticismo mitigado. Uma tal modalidade de ceticismo não seria uma posição radical contra o conhecimento absoluto, nem tampouco se confundiria com o ceticismo pirrônico. Portanto, o ceticismo mitigado de Hume tem a característica de ser uma atitude filosófica que emprega a dúvida moderada com o propósito de questionar a possibilidade do conhecimento humano.

\section{CONSIDERAÇÕES FINAIS (ou Conclusão)}

Nossa pesquisa examinou a crítica de David Hume à noção de causalidade apresentada no Tratado da Natureza Humana. Tendo em vista o lugar ocupado pelo naturalismo na obra e na maneira como as questões são formuladas e respondidas pelo autor foi possível reconstituir as exigências conceituais à luz das quais Hume faz ver que a noção de necessidade não pode ser aplicada indistintamente aos domínios das ciências empíricas e das matemáticas. Por esta razão, Hume põe em xeque a concepção de necessidade adequada ao domínio da experiência, recorrendo ao amparo da noção de natureza humana nas Investigações sobre o entendimento humano de 1748. A exploração dessa perspectiva permite compreender as diferenças entre o Tratado e as Investigações como muito mais uma questão de ênfase que, como tal, não significa a abolição da unidade da obra, significando, ao contrário, a sua riqueza e aquilo que ela tem de mais radical: uma crítica à razão.

\section{REFERÊNCIAS}

ALQUIÉ, Ferdinand. A ideia de causalidade de Descartes a Kant. In: CHÂTELET, François (Org.). História da filosofia: ideias, doutrinas. Vol. 4. Tradução Guido de Almeida. Rio de Janeiro: Zahar Editores, 1982.

BERKELEY, George. Tratado sobre os princípios do conhecimento humano. In: Hume, D. Tradução de Antônio Sérgio. 2. ed. São Paulo, Abril Cultural, 1980. - (Os pensadores).

CHISHOLM, Roderick M. Teoria do conhecimento. Tradução de Álvaro Cabral. Rio de Janeiro: Zahar editores, 1969.

COVENTRY, Ângela M. Compreender Hume. Tradução de Hélio Magri Filho. 2. ed. Rio de Janeiro: Vozes, 2011. - (Série Compreender). 
DELEUZE, Gilles. Empirismo e subjetividade: ensaio sobre a natureza humana segundo Hume. Tradução de Luiz Orlandi. São Paulo: Ed. 34, 2001. - (Coleção TRANS).

FOGELIN, R. J. A tendência do ceticismo de Hume. Tradução de Plínio Junqueira Smith. In: SKÉPSIS, s. 1, v. 1, n. 1, p. 99-118, 2007.

HACKER, P. M. S. Wittgenstein: sobre a natureza humana. Tradução de João Vergílio Gallenari Cuter. São Paulo: Editora UNESP, 2000. - (Coleção Grandes Filósofos).

HUME, David. Da imortalidade da alma e outros textos póstumos. Tradução de Daniel Swoboda Murialdo, Davi de Souza e Jaimir Conte. Ijuí: Ed. Uninjuí, 2006. (Coleção filosofia; 12).

Investigações sobre o entendimento humano e sobre os princípios da moral. Tradução de José Oscar de Almeida Marques. São Paulo: Ed. Unesp, 2004.

Resumo de um Tratado da natureza humana. Tradução de Rachel Gutiérrez e José Sotero Caio. Ed. bilíngue. Porto Alegre: Edições Paraula, ed. Bilíngüe, 1995.

São Paulo, Ed. Unesp, 2009.

. Tratado da natureza humana. Tradução de Débora Danowski. 2. ed.

KANT, Immanuel. Prolegómenos a toda metafísica futura: que queira apresentar-se como ciência. Tradução de Artur Morão. Lisboa: Edições 70, 2008.

LEBRUN, Gérard. Hume e a astúcia de Kant. In: Sobre Kant. Tradução de José Oscar Almeida Marques, Maria Regina Avelar Coelho da Rocha, Rubens Rodrigues Torres Filho. 3. ed. São Paulo: Iluminuras, 2010. - (Biblioteca Pólen).

MARCONDES, Danilo. Iniciação à história da filosofia: dos pré-socráticos à Wittgenstein. $2^{\mathrm{a}}$ ed. Rio de Janeiro: Zahar, 2007.

MONTEIRO, João Paulo. Associação e crença causal em David Hume. In: Novos estudos humeanos. São Paulo: Discurso Editorial, 2003.

2009.

Hume e a epistemologia. São Paulo: Editora Unesp; Discurso Editorial, 111-128, jan./jun. 2005.

MOURA, Carlos Alberto Ribeiro de. David Hume para além da epistemologia. In: Racionalidade e crise: estudos de história da filosofia moderna e contemporânea. São Paulo: Discurso Editorial e Editora do UFPR, 2001.

SALLES, João Carlos. Naturalismo e Filosofia em David Hume. In: Cad. Hist. Fil. 